\title{
Desenvolvimento de Tecnologias Assistivas Para Imersão de Deficientes Visuais em Ambientes Educacionais
}

\author{
Gbson R. Scantlebury ${ }^{1}$, Leonardo P. Vieira ${ }^{1}$, Emmerson S. R. Silva ${ }^{1,2}$, Jucimar B. \\ Souza ${ }^{1}$ \\ ${ }^{1}$ Instituto Federal de Educação, Ciência e Tecnologia do Amazonas - Campus Manaus \\ Centro (IFAM-CMC) - Manaus - AM - Brasil \\ ${ }^{2}$ Universidade Tecnológica Federal do Paraná (UTFPR) - Curitiba - PR - Brasil \\ scantleburyrodrigues@gmail.com, leonardo.vieira.lpv2@gmail.com, \\ emmsr2004@gmail.com, jucibs@gmail.com
}

\begin{abstract}
This paper implements low-cost residential automation resource to assist the visually impaired based on the Arduino platform, and with implementation based on assistive technology concepts to enable the inclusion of the visually impaired in the academic environment. Context-sensitive automation increases the degree of accessibility of an environment by allowing it to be a proactive agent and to act intelligently, anticipating the various situations with solutions that benefit its users. The developed system allows the user to use the classroom, through local and remote communication interfaces, based on Arduino, enabling it to execute in a pervasive way.
\end{abstract}

Resumo. Este artigo implementa recursos de automação residencial de baixo custo para auxiliar deficientes visuais, baseados na plataforma Arduino, e com implementação baseada nos conceitos das tecnologias assistivas de modo a possibilitar a inclusão do deficiente visual no meio acadêmico. A automação sensivel ao contexto aumenta o grau de acessibilidade de um ambiente, pois o permite que seja um agente proativo e aja de maneira inteligente, se antecipando as diversas situações com soluções que beneficiam seus usuários. O sistema desenvolvido permite que o usuário utilize a sala de aula, por meio de interfaces de comunicação locais e remotas, baseado em Arduino, possibilitando que este execute de modo pervasivo.

\section{Introdução}

Tecnologia Assistiva é um termo utilizado para identificar os recursos e serviços que contribuem para proporcionar ou ampliar habilidades funcionais de pessoas com deficiência e consequentemente promover independência e inclusão. Dessa forma, tornase possível a integração e o melhor aproveitamento do aluno com deficiência em sala de aula, uma vez que o mesmo não pode ser segregado ou afastado do convívio dos outros colegas levando em consideração o conceito de inclusão (COOK, 2005).

Atualmente o Brasil dispõe de diversas normas no que se diz respeito à acessibilidade, sendo uma delas a NBR 9050 (ABNT, 2004), que define Acessibilidade como "possibilidade e a condição de utilizar, com segurança e autonomia, os edifícios, o espaço, o mobiliário e os equipamentos urbanos", além da Lei 10.098 (BRASIL, 2000), que estabelece as normas gerais e critérios básicos para promoção da acessibilidade às pessoas com deficiência. 
A Automação Inclusiva tem como foco a acessibilidade, segurança, saúde e bemestar das pessoas que residem ou frequentam determinado ambiente (GUEDES et al, 2012). Apesar de proporcionar muitos benefícios aos seus usuários, recursos de automação residencial possuem custo de implantação muito elevado, e um dos motivos desse alto custo é a necessidade de hardwares específicos para o controle residencial (MOZER, 2005). Para diminuir os valores de implantação de recursos de automação, surge a possibilidade de utilizar uma categoria de hardware recente no mundo da computação denominada open-source hardware (OSH), ou hardware livre.

O presente trabalho tem por objetivo utilizar a domótica (TONIDANDEL, 2004) com o fim de proporcionar acessibilidade e inclusão aos deficientes visuais, por meio de um sistema simplificado, composto por hardware de baixo custo, que atenda às necessidades de seus usuários.

\section{Proposta}

Com o objetivo de promover acessibilidade, inclusão e independência aos alunos com deficiência visual, tem-se como proposta a construção de uma sala de aula pensada no princípio do Desenho Universal (SASSAKI, 1997), na qual todos os alunos serão contemplados com um ambiente acadêmico inteligente.

A sala de aula contará com recursos de automação residencial, que tornarão automáticas atividades cotidianas, como: abrir/fechar portas e janelas; controle de climatização; ligar/desligar luzes com base nas informações recebidas pelo sensor de luminosidade; computadores e hardwares externos controlados por voz. Na Figura 1, representamos esquematicamente a automação das portas (1), iluminação (2) e ar condicionado (3).

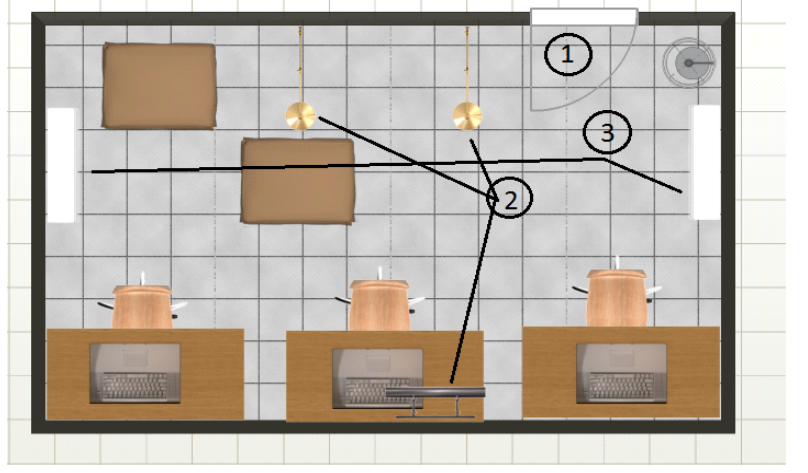

Figura 1. Projeto do Sistema de automação da sala de aula

O sistema contará também com dispositivo de reconhecimento de voz, que permitirá ao usuário que ligue ou desligue um computador mediante a pronúncia de um comando. O computador, ao ser iniciado pelo usuário, possuirá um software de acessibilidade para deficientes visuais, para que o aluno possa receber por meio do software, a descrição audível de todos os sistemas virtuais que possa vir a utilizar.

Para a maioria das pessoas, este tipo de tecnologia pode ser considerado meramente um artigo de conforto, mas para usuários com necessidades especiais, o comando de voz pode facilitar a execução de atividades rotineiras (PERICO, SHINOHARA, SARMENTO, 2014), por exemplo. 


\section{Aplicação}

O sistema é aplicado na plataforma Arduino, mais especificamente no Arduino Uno R3, que oferece uma interface de hardware proporcionando todo o circuito necessário para funcionamento do micro controlador e uma interface e ambiente de desenvolvimento em software para programação. Por ser uma plataforma de código aberto (open-source) há uma grande comunidade de desenvolvedores do mundo inteiro que disponibilizam bibliotecas de código para ser aplicado nessas plataformas, com funções específicas, como, por exemplo, o controle de servo motores ou leitura de sensores analógicos. (CARVALHO, 2011, p. 34).

As imagens a seguir (Figura 2), apresentam os testes feitos com a maquete do ambiente que contém o sistema:

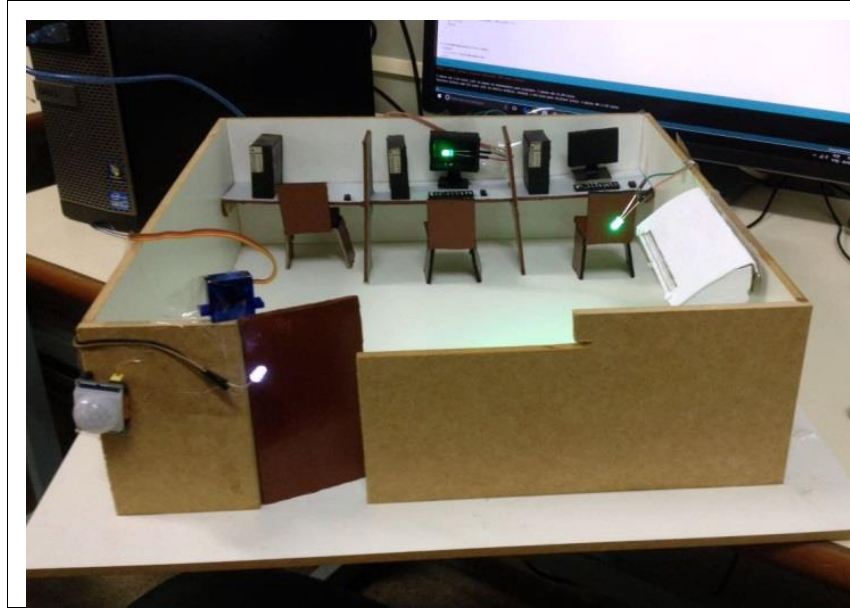

(a)

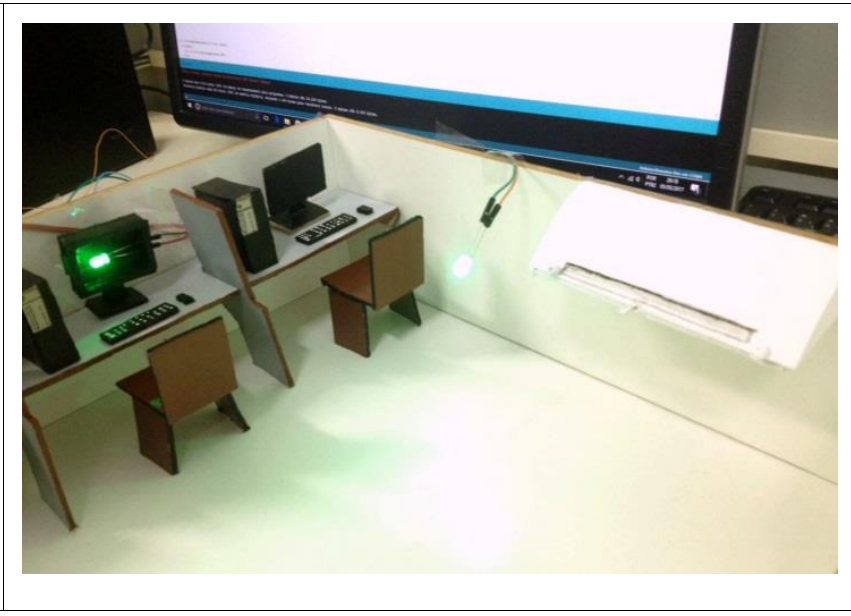

(b)

Figura 2. - (a) Testes com a porta da sala de aula. (b) Teste com o sistema de controle de temperatura e computadores.

A Figura 2 apresenta a maquete com os componentes ainda em fase de calibração dos sensores, que está sendo utilizada para os ensaios iniciais. O sistema instalado na maquete funciona da seguinte forma: o sensor de presença PIR, localizado ao lado da porta (figura 2 (a)) irá detectar a presença do usuário em frente à sala, e, em seguida, ativar o Servo Motor apensado à porta, que irá abri-la possibilitando a entrada do usuário, e em seguida, fechá-la.

É também utilizado o Sensor de Luminosidade LDR, que é responsável pelo controle de iluminação, variando sua resistência de acordo com a intensidade da luz presente no ambiente, ligando ou desligando o LED (diodo emissor de luz) que representa a iluminação de acordo com a necessidade. De forma semelhante funciona o controle do ar condicionado, que utiliza o Sensor de Temperatura DHT11 para verificar a temperatura, e de acordo com as necessidades do ambiente, liga ou desliga o LED que representa $o$ ar condicionado. $O$ LED que nas imagens da maquete representa $o$ computador é ligado por meio de um botão localizado no protoboard do sistema, mas posteriormente será ativado por meio de um sensor de reconhecimento de voz.

\section{Trabalhos Futuros}

As próximas etapas do projeto são integrar ao sistema de automação, recursos relacionados a emergência, como no caso de incêndios, para que o deficiente visual possa ser guiado para fora do ambiente em segurança, por meio de recursos sonoros. 
Têm-se também como próximos passos, a implementação do sistema em um ambiente real, para que possa ser avaliado por deficientes visuais, e aprimorado de acordo com as necessidades que surgirem.

\section{Considerações Finais}

O sistema em desenvolvimento tem como objetivo auxiliar alunos com deficiência visual, possibilitando tanto a acessibilidade ao ambiente acadêmico, melhorando a execução de suas atividades cotidianas, quanto melhorando a acessibilidade aos sistemas que irão auxiliá-lo no processo de ensino-aprendizagem.

O ambiente que contém o sistema utiliza sensores e controladores que funcionam por meio de uma placa programável, que possibilita a automação do ambiente, proporcionando o fácil e instantâneo acesso às funcionalidades do ambiente propriamente dito.

\section{Referências}

ABNT: ASSOCIAÇÃO BRASILEIRA DE NORMAS TÉCNICAS. Norma NBR 9050, Acessibilidade a Edificações, Mobiliário, Espaços e Equipamentos Urbanos. Rio de Janeiro, 2004.

BRASIL. Lei n 10.098 , de 19 de dezembro de 2000. Estabelece normas gerais e critérios básicos para a promoção da acessibilidade das pessoas com deficiência ou com mobilidade reduzida e dá outras providências. Brasília, DF, Congresso Nacional, 2000.

CARVALHO, Mauricio Feo Pereira Rivello de. Automação e controle residencial via internet utilizando arduino. In: SEMANA DE EXTENSÃO, 1., Rio de Janeiro. Anais... Rio de Janeiro: [online], 2011.

COOK, A.M. \& HUSSEY, S. M. (1995). Assistive Technologies: Principles and Practices. St. Louis, Missouri. Mosby - Year Book, Inc.

GUEDES, Lucas et al. O papel social da automação: automação inclusiva e mais sustentável. In: SEMINÁRIO NACIONAL DE CONSTRUÇÕES SUSTENTÁVEIS. Passo Fundo, 2012

MOZER, M. The adaptive house. In: Intelligent Building Environments, 2005. The IEESeminar on (Ref. No. 2005/11059). [S.1.: s.n.], 2005. p. 39-79. ISSN 0537-9989.

PERICO, A., SHINOHARA, C. S., SARMENTO, C. D. (2014). Sistema de Reconhecimento De Voz Para Automação De Uma Plataforma Elevatória.

SASSAKI, Romeu Kazumi. Inclusão: construindo uma sociedade para todos. Vol. 174. Rio de Janeiro: Wva, 1997.

TONIDANDEL, F., TAKIUCHI, M., MELO, E. (2004). Domótica Inteligente: Automação baseada em comportamento. Congresso Brasileiro de Automática. 